УДК 001.92

DOI: $10.17223 / 23062061 / 18 / 2$

\title{
В.Н. Горенинцева
}

\section{СТРАТЕГИИ ПЕРЕВОДА КРОССОВЕР-ЛИТЕРАТУРЫ (НА МАТЕРИАЛЕ РУССКОЯЗЫЧНЫХ ВЕРСИЙ ЭПИЧЕСКОГО ФЭНТЕЗИ Р. АДАМСА «ОБИТАТЕЛИ ХОЛМОВ»)}

Аннотация. На материале романа Р. Адамса «Обитатели холмов» и его переводов рассматривается проблема трансляции кроссовер-литературы, обусловленная размыванием в ней традииионных грании возрастной адресаџии. Утверждается, что выбор переводческой стратегии в этом случае определяется скопосом перевода и возрастной категорией целевой аудитории, а продуктом деятельности переводчика становится как собственно перевод, так и адаптация, которую можно считать равноправным репрезентантом оригинала в принимающей культуре.

Ключевые слова: кроссовер-литература, универсальная адресация, скопас перевода, инициатор перевода, стратегии адаптаичи, перевод для детей.

Одной из тенденций последних десятилетий становится стирание критериев возрастной адресации литературного произведения. Раньше читатель, несмотря на все многообразие жанров, ориентировался внутри бинарной оппозиции «взрослое - детское», не испытывая особых трудностей, и, как утверждают И.Н. Арзамасцева и С.А. Николаева, мог «по одной строфе или даже стиху, по одному абзацу или фразе определить читательскую адресацию текста, поскольку образ читателя-ребенка пронизывал все произведение» [1. С. 17]. В настоящее время классификация литературы на «детскую» и «не-детскую» не представляется столь легкой задачей, поскольку авторы все чаще сознательно пишут книги с двойной или универсальной адресацией («cross-writing») или, по наблюдению О.Н. Мяоэтс, вообще уходят «играть на детскую террито-

${ }^{1}$ Исследование выполнено при финансовой поддержке РФФИ (РГНФ) в рамках научного проекта № 17-03-00528 «Семейное чтение как помогающая практика в условиях социально-культурных трансформаций». 
рию» [2. С. 170]. Писатели намеренно избегают возрастной поляризации и создают особое пространство взаимодействия читателей всех возрастов. Можно утверждать, что на современном этапе на книжном рынке сформировался особый сегмент гибридной литературы, названной кроссовер-литературой («crossover fiction»), основной характеристикой которой, по определению С. Беккет, является размывание традиционных границ возрастной адресации [3. Р. 3]. Несмотря на относительную новизну термина (впервые он появился в англоязычных СМИ в 1990-х гг. после публикации первой книги серии о Гарри Поттере Дж. Роулинг), само явление имеет давнюю историю. Потенциалом универсальной адресации обладают народные и волшебные сказки, басни и мифы. Многие произведения литературной классики, создававшиеся для взрослой аудитории, часто находили путь к читателю-ребенку в виде адаптаций, пересказов и переложений. С другой стороны, классика детской литературы, к примеру, произведения А. Милна, Л. Кэррола, К.С. Льюиса, К. Грэма, в равной степени интересны и востребованы среди взрослых читателей. В XXI в. кроссоверлитература выступает как один из основных трендов литературного рынка, являясь одновременно частью более широкого культурного контекста, включающего фильмы, телевизионные шоу, видео и компьютерные игры.

Произведения кроссовер-литературы возникают при совмещении двух структурных моделей: архетипической, обращенной к читателю-ребенку, и усложненной, экспериментальной, обращенной к взрослому читателю, вырастающей из переосмысления, адаптации, пародирования первой модели и создаваемой с использованием сложных нарративных приемов (жанровой гибридизации, множественной фокализации, метаповествования и т.д.). При переносе в инокультурную среду двуплановость текста создает потенциал для переадресации произведения: поскольку кроссоверлитература не только жанровая, но и маркетинговая категория, возникают разные ситуации, когда кроссовер-потенциал произведения не сохраняется автоматически, а стратегия перевода будет зависеть от поставленной перед переводчиком цели. Согласно тео- 
рии К. Райс и Х. Фермеера, именно скопос, т.е. цель и функции переводного текста в принимающей культуре, формулируемые инициатором перевода (заказчиком, издателем, автором, иногда переводчиком), имеют решающее влияние на решения, принимаемые переводчиком [4. Р. 54]. Исходя из читательски-ориентированного определения жанра кроссовер-литературы и заложенного в ней потенциала универсальной адресации, определяющим фактором при формулировании скопаса перевода становится целевая аудитория, поскольку, как утверждает К. Норд, «перевод всегда адресован кому-то и выполняет определенную функцию, даже если оригинальный текст создавался без какой-либо конкретной цели или намерения» [5. Р. 83]. При этом целевая аудитория в данном случае не является какой-то обобщенной категорией, а представляет запланированную инициатором перевода целевую «аудиторию-в-ситуации», имеющую совершенно определенные характеристики [6. Р. 24]. В случае, когда издатель планирует выпустить произведение в сегменте кроссовер-литературы, от переводчика естественно ожидать стремление максимально сохранить двуединство «детского» и «взрослого» планов текста. Если принято решение о позиционировании произведения в сегменте детской литературы, перед переводчиком возникают особые задачи, обусловленные спецификой детской литературы и перевода для детей.

Принадлежа одновременно двум системам - художественноэстетической и социально-образовательной, детская литература многофункциональна и, в отличие от «взрослой» литературы, в большей степени регламентирована. Являясь мощнейшим инструментом социализации, она транслирует ценности, нравственные ориентиры, социальные и культурные нормы, характерные для разных стран в разные эпохи. Поскольку переводные произведения также должны вписаться в систему ценностей реципиента, переводчику приходится адаптировать оригинал для создания сообщения, адресованного новой аудитории с ее особыми социолингвистическими потребностями. Вопрос о статусе адаптации в детской литературе до сих пор является дискуссионным, причем отношение к адаптации варьируется от полного неприятия и осуж- 
дения до признания неизбежности. Противники адаптации, или «одомашнивания», в переводе детской литературы утверждают, что такой подход лишает детей нового знания о мире [7. Р. 58] и является знаком неуважения к читателю-ребенку [8. Р. 28]. С другой стороны, Дж.Л. Бастин понимает адаптацию при переводе детской литературы как «набор трансляционных вмешательств», в результате которых текст, тем не менее, признается как репрезентант исходного текста [9. Р. 3]. По мнению Т. Пууртинен, адаптация при переводе для детей неизбежна, поскольку детская литература регулируется многочисленными ограничениями, варьирующимися от культуры к культуре [10. Р. 525]. Р. Ойтиннен считает адаптацию формой перевода, представляющей собой, как и перевод, переписывание текста для новой целевой аудитории. Таким образом, по мнению исследователя, любой перевод можно считать адаптацией («одомашниванием»), поскольку за каждым переводческим решением стоит представление о будущем читателе и о функции текста в принимающей культуре. Ойтиннен утверждает, что переводчик может адаптировать оригинал с учетом особенностей читателя-ребенка и оставаться при этом лояльным автору, если ему удается в переводе создать такой текст, «через который оригинал будут любить в принимающей культуре» [11. Р. 76-77].

При переводе произведения кроссовер-литературы с целью последующего выпуска книги в детском сегменте адаптация представляется неизбежной. Полученный продукт в этом случае чаще всего маркируют как сокращенный / адаптированный перевод, пересказ или переложение. При этом наибольшим трансформациям подвергается «взрослый план» художественного текста: оригинал приспосабливается к существующей в принимающей культуре жанровой модели детской литературы, осуществляются манипуляции с целостностью, уровнем сложности и стилистикой текста, изменяется этико-аксиологический компонент. 3. Шавит выделяет две основные причины для такого «одомашнивания» текста в переводе для детей. Во-первых, когда ведущей функцией детской литературы в принимающей культуре является дидактическая, приспособление текста осуществляется в соответствии с приняты- 
ми в обществе образовательными и нравственными нормами: переводчик изменяет текст, чтобы сделать его «хорошим и полезным» в соответствии с тем, что считается таковым в принимающей социокультуре. Во-вторых, если дидактическая функция не рассматривается как основная, при переводе может произойти приспособление сюжета, персонажей и языка произведения в зависимости от когнитивных способностей и читательского опыта ребенка в культуре-реципиенте. Иногда, замечает Шавит, происходит столкновение этих двух принципов, но чаще всего они дополняют друг друга и диктуют как выбор текста для перевода, так и «весь комплекс манипуляций», к которому прибегает переводчик [12. P. 112-113].

Эпическое фэнтези британского писателя Р. Адамса «Обитатели холмов» (Richard Adams, Watership Down, 1972) [13] считается классикой британской детской литературы XX в. В романе, представляющем собой переработанное собрание сказок, которые писатель рассказывал своим дочерям во время поездок по стране, рассказывается о приключениях диких кроликов, покинувших свою колонию и отправившихся на поиски нового дома. Испытывая влияние трудов по сравнительной мифологии Дж. Кэмпбелла [14], в свою очередь уходящей корнями к юнгианским архетипам и коллективному бессознательному [15], Адамс создает «кроличий» мономиф со всеми присущими характеристиками: герой (кролик Орех) покидает знакомую территорию и отправляется в путь, на котором он, пройдя многочисленные испытания, преображается и в конечном итоге присоединяется к сонму богов, чтобы дать начало новому мифу. Спутники Ореха и другие персонажи романа также представляют определенные архетипы: среди них есть Воин (кролик Лохмач), Шаман (Пятик), Мудрец (Смородина), Сказитель (Одуванчик), Антагонист (Генерал Дурман), Трикстер (ЭльАхрайрах). В романе переплетаются многочисленные мифологические, сказочные и эпические мотивы. Исследователи обнаруживают в «Обитателях холмов» прямые параллели с «Энеидой» Вергилия и «Одиссеей» Гомера, реализованные через прямые сюжетные заимствования, на уровне прототипизации персонажей и в 
форме своеобразной игры с читателем, ведущей к переосмыслению роли эпоса и эпического героя в современном мире $[16,17]$. Так, Дж. Рателифф считает, что Адамс создает альтернативную версию «Энеиды»: как могли бы развиваться события, если бы Кассандре (у Адамса кролику Пятику, обладающему даром предвидения) поверили и народ смог бы покинуть Трою (Сэндлфордскую кроличью колонию) до того, как она была разрушена [18]? Предваряя каждую главу эпиграфом-подсказкой, раскрывающей сюжетную перспективу, Адамс вводит свое произведение в широкий контекст мировой художественной литературы и культуры: среди цитируемых авторов Эсхилл, Ксенофонт, Вергилий, Гомер, Шекспир, У.Б. Йейтс, Р. Браунинг, Дж. Баньян, Т. Мэлори, У.Х. Оден, У. Блейк, У. Конгрив, Дж. Кэмпбелл, Дж. Остин, Ф.М. Достоевский, «детские» авторы К. Грэм, Дж.Ч. Харрис, Л. Кэрролл, а также анонимные цитаты из публицистических текстов, фельетонов, песенок из популярных мюзиклов, американских народных песен, романтических баллад. Создавая более чем увлекательное повествование, Адамс включает в ткань романа свои рассуждения об устройстве мира, человеческой природе, жизни и смерти, социальных проблемах. Эффект реалистичности происходящего усиливается и благодаря тому, что в описании кроличьего быта Адам опирается на труд британского натуралиста Р. Локли «Частная жизнь кролика» [19]. Как и Локли, Адамс романтизирует своих героев, представляет кроличье общество как модель человеческого: хотя кролики у него живут в естественной среде, не носят одежду и не имеют человеческих привычек, у них есть своя культура, игры, фольклор, боги и герои, поэзия, мифология. Адамс изобретает особый кроличий язык - «лапинь», состоящий из нескольких десятков различных слов, используемых в основном для обозначения привычек, мифологических персонажей и объектов кроличьего мира. Другие анималистические персонажи романа (мышь, буревестник) также говорят с узнаваемым акцентом. Неологизмы вводятся с изначальным объяснением и переводом, затем неоднократно используются в повествовательной ткани романа. Не позволяя читателю забыть, что персонажи - кролики, 
Адамс индивидуализирует своих героев, наделяя каждого узнаваемой личностью, и создает полноценный мир, отличающийся сложным устройством: здесь есть демократии, диктатуры, социальное расслоение и классы. Соединяя эпос, фэнтези и каноны детской литературы, писатель моделирует особое пространство: действие развивается в привычном для людей мире, но читатель видит его под новым углом, через перспективу кроличьего восприятия, совершая удивительное открытие о том, что человеческий мир не единственный. О сложности произведения свидетельствуют его многочисленные интерпретации: «Обитателей холмов» относили к научным произведениям, объединяющим художественную и научную культуру [20], называли политическим трактатом [21. Р. 9-10], аллегорией с архетипическим сюжетом [22], произведением о «выживании интуитивного человека в его конфликте с современными технологиями и индустриальной цивилизацией» [23. Р. 7].

Роман Р. Адамса имел огромный успех у читателей и рецензентов, получил ряд престижных наград, среди которых медаль Карнеги. Однако критики долгое время не могли прийти к общему мнению о возрасте целевой аудитории произведения. Изначально книга получила теплый прием критиков именно как произведение для детей. В журнале «Economist» анонимный рецензент писал, что если «Обитателям холмов» нет места в детской литературе, то «детская литература мертва» [24]. Однако нельзя было однозначно считать роман Адамса детским из-за сложного языка, поднимаемых автором «недетских» тем смерти, тирании, выживания и продолжения рода, а также обилия натуралистических описаний и жестоких сцен (к примеру, кролики, умирающие от отравления газом; пытки, которым подвергаются герои, восставшие против диктатора Дурмана, и т.д.).

На русский язык роман Р. Адамса переводился дважды. Первый перевод-пересказ Е.В. Догель вышел в советском издательстве «Детская литература» в 1988 г. [25]. При публикации издательство определило жанр произведения Адамса как повесть-сказку, ограничив целевую аудиторию средним школьным возрастом. Из аннотации к изданию, имеющей выраженный дидактический харак- 
тер, читатель узнавал, что в книге «в сказочной форме разоблачается насилие, социальная несправедливость, провозглашаются принципы добра, честности, равноправия» [25. С. 2]. В соответствии с выбранной жанровой принадлежностью подвергается адаптации заглавие произведения: вариант Е.В. Догель «Удивительные приключения кроликов» эксплицирует сюжетную перспективу и звучит понятно и привлекательно для детей. Сигнал подкрепляется внетекстовыми компонентами: оформлением обложки, декоративными изображениями, орнаментами и иллюстративным рядом, стилизованным под детские рисунки. Художник Ю. Бочкарева создает сказочный мир забавных игрушечных зверей, которые, вопреки авторскому замыслу, очеловечены: они носят одежду и ходят на задних лапах.

Второй перевод, выполненный Т.Н. Чернышовой, был опубликован в 1996 г. издательством «Азбука-Терра» [26]. В аннотации к нему произведение Адамса определяется как «эпический роман», который будет интересен читателям «от восьми до восьмидесяти лет», что демонстрирует намерение издательства продвигать книгу в сегменте кроссовер-литературы. Вариант заглавия «Обитатели холмов» (либо «Корабельный холм» в последующих изданиях) в переводе Т.Н. Чернышовой максимально приближен к оригиналу и также рассчитан на универсальную аудиторию. На обложки изданий разных лет обычно помещают кроликов на фоне пасторального пейзажа, а иллюстративный ряд отсутствует.

Сравнительно-сопоставительный анализ русскоязычных перевода и пересказа романа Р. Адамса демонстрирует, что в обоих случаях переводчики действуют в рамках скопоса, определенного инициатором перевода, в данном случае издательством: Чернышова стремится создать перевод, коммуникативно адекватный оригиналу, в то время как Догель, ориентируясь на детскую читательскую аудиторию - учеников советской средней школы, - существенно «одомашнивает» текст, прибегая к различным манипулятивным техникам.

Прежде всего, если перевод Чернышовой является целостным репрезентантом оригинала, то в пересказе Догель оригинал суще- 
ственно сокращен. Приспосабливая исходный текст к заданной скопосом модели приключенческой повести-сказки, переводчик, с целью усиления динамики повествования, исключает фрагменты, не участвующие в развитии сюжетной линии напрямую. Роман Адамса включает пространные пейзажные зарисовки, выступающие одновременно как средство характеристики эмоционального состояния персонажей и как способ моделирования утопической реальности, альтернативной деструктивному воздействию урбанизации и индустриального общества. Описания английского сельского пейзажа в романе Адамса не только указывают на «путь к спасению», но и исподволь формируют консервативное мировоззрение, где во главу угла поставлен традиционный жизненный уклад [27. Р. 220]. В пересказе Догель описания пасторальных пейзажей существенно сокращаются или остаются вообще непереведенными, поскольку замедляют быструю смену занимательных событий, т.е. именно то, что больше всего нравится детям. Стремление адаптировать оригинал в соответствии с предполагаемой степенью сформированности языковой личности потенциального читателя-ребенка и объемом его знаний об окружающем мире приводит к упрощению авторских подстрочных комментариев, объясняющих явления из кроличьей жизни. Комментарии в пересказе Догель сокращаются в объеме, из них убираются отсылки к прецедентным именам и ситуациями, которые могут оказаться незнакомыми ребенку, в то время как перевод Чернышовой приближен к оригиналу. На этом же основании переводчик исключает все эпиграфы к главам: цитируемые произведения не входили в круг чтения советского ученика среднего школьного возраста, а значит, не могли служить основой для интертекстуальной игры, в результате которой читатель мог испытать «радость узнавания».

Показательным примером адаптации является сокращение ольфакторной единицы, создающей у читателя оригинала своеобразный «мост» с памятью через вербализацию обонятельных ощущений: «The strange fragrance was stronger now, coming over the top of the rise in a wave of scent that struck him powerfully - as the scent of orange blossom in the Mediterranean strikes a traveler who smells it 
for the first time» (здесь и далее курсив наш. - В.Г.) [13. Р. 43]. Догель исключает соответствующий одоризм как не обеспечивающий эффект узнавания: вряд ли советский ребенок имел возможность бывать на Средиземном море и вдыхать аромат цветущих апельсинов, в то время как в переводе Т.Н. Чернышовой ольфакторная единица сохраняется:

Пересказ Е.В. Догель Из-за холма по-прежнему неслись волны странного аромата, становившегося все отчетливей [25. C. 29].
Перевод Т.Н. Чернышовой Необычное благоухание усилилось, обрушившись на Ореха мощными волнами, шедшими с вершины склона. Так на путешественника, который впервые попал на побережье Средиземного моря, обрушивается волнами аромат апельсиновых рощ [26. C. 54].

Упрощение оригинала в пересказе Догель осуществляется и посредством других переводческих трансформаций. К примеру, на лексико-синтаксическом уровне текст становится более приспособленным для детского чтения и ориентированным на ребенка за счет подбора более удобопроизносимых лексических единиц, простых синтаксических структур, перевыражения сложных цепочек из причастных оборотов, а также благодаря активному использованию переводчиком уменьшительно-ласкательных форм. Для снятия возможных трудностей в запоминании единиц изобретенного Адамсом кроличьего языка «лапинь» Догель прибегает к дублирующему переводу, добавляя к окказионализмам знакомое детям параллельное наименование: «Солнце-Фрис», «лендрибарсук», «йона-ежик». Чернышова, в свою очередь, практически не использует дублирующий перевод. Наконец, симплификацию можно наблюдать на уровне стилистики текста. Так, описывая кроличью версию мифа о Сотворении мира, Адамс на синтаксическом уровне стилизует текст под библейский, используя эмфазу, повторы и библейско-эпическое «и» в начале фраз:

And all the creatures set out to go to the meeting place. $<\ldots>$ And when the blackbird came, he gave him his beautiful song. And when the cow 
came, he gave her sharp horns and the strength to be afraid of no other creature. And so in their turn came the fox and the stoat and the weasel. And to each of them Frith gave the cunning and the fierceness and the desire to hunt and slay and eat the children of El-ahrairah. And so they went away from Frith full of nothing but hunger to kill the rabbits [13. P. 26].

В переводе Чернышовой стилизация сохраняется частично, в то время как в пересказе Догель аллюзия не прочитывается:

Пересказ Е.В. Догель Когда пришел дрозд, он получил чудесную песню, а когда пришел бык, он получил неустрашимость. В свою очередь пришли горностай, лиса и ласка. Каждому из них Фрис подарил страстное желание пожирать детей Эль-Эхрейры [25. C. 18].
Перевод Т.Н. Чернышовой И все твари живые пришли к тому месту, куда велел Фрит. <...> И когда пришел дрозд, Фрит подарил ему прекрасную песню, $a$ когда пришел бык, дал быку рога и силу, чтобы никого не бояться. $A$ потом по очереди пришли лиса, горностай и ласка. И он дал им хитрость, жестокость $u$ жажду охоты $u$ приказал убивать детей ЭльАхрайраха $u$ кормиться ими [26. C. 37].

Наконец, этико-аксиологическая адаптация в пересказе Е.В. Догель осуществляется путем «санации» оригинала. Переводчик имплицитно формирует детское мировоззрение, подвергая замене, сокращению или перевыражению элементы текста, которые, по мнению взрослых, не соответствуют морально-этическим нормам принимающей социокультуры и, соответственно, являются неприемлемыми для советской детской литературы, которая должна была решать дидактическую задачу, объясняя ребенку, что хорошо и что плохо. У Догель такой цензуре на разных уровнях текста и в разном объеме подвергаются половые отношения, телесность, экскременты, физические оправления, насилие, религиозные мотивы, пугающие предметы или события. К примеру, на лексическом уровне для перевода английских лексем «buck» и «doe» (рус. «caмец» и «самка») Догель выбирает более подходящие для детской сказки варианты «кролик», «крольчиха / мамаша»; английский 
глагол «to mate» (русс. «спариваться (о животных)») заменяется на «заключать брак, жениться».

На тематическом уровне переводчик убирает из пересказа неприемлемую для детского чтения тему многоженства, адаптируя к детскому чтению миф о кроличьем прародителе Эль-Ахрайрахе и трансформируя кролика-трикстера в заботливого отца, в то время как перевод Чернышовой следует оригиналу:

Пересказ Е.В. Догель

У него было столько детей, что их не сумел бы сосчитать сам Фрис. И все они питались травой и одуванчиками, салатом и клевером, а Эль-Эхрейра был им всем отизом [25. С. 18].
Перевод Т.Н. Чернышовой $<\ldots>$ и было у него много жен. У него было так много жен, что не рассказать, а у жен - так много детей, что сам Эль-Ахрайрах не знал им счета, и все они ели траву, одуванчики, клевер, салат, $a$ Эль-Ахрайрах был им отеи [26. C. 37].

В другом случае Догель приспосабливает для детского чтения неблагозвучную версию кроличьего мифа о Сотворении мира, связанную с описанием естественных оправлений, в то время как Чернышова придерживается оригинала:

Пересказ Е.В. Догель В незапамятные времена Солнце-Фрис сотворил нашу Землю [25. С. 18].
Перевод Т.Н. Чернышовой Давным-давно сотворил Фрит землю. Сотворил он еще и звезды, а земля наша тоже звезда. А чтобы сотворить их, он разбросал свой помет по всему небу, потому и растут теперь на земле такие большие деревья да такая густая трава [26. С. 37].

Догель полностью исключает эпилог, рассказывающий о смерти протагониста, кролика Ореха, который, состарившись, был призван на службу прародителем кроликов Эль-Ахрайрахом, т.е. отправился в «кроличий» рай. У Р. Адамса смерть Ореха не выглядит трагичной или героической, а предстает неотъемлемой частью 
жизненного цикла. Однако советская детская литература, одной из основных черт которой считался оптимизм, признавала лишь разговор о героической смерти, в то время как все остальные «виды» смерти (например, смерть в мирное время или по старости) принадлежали частной человеческой жизни и поэтому считались недостойными разговора [28]. Более того, идеологически неприемлемым было любое упоминание о небесном рае и жизни после смерти. В отличие от сокращенного перевода Догель, перевод Чернышовой включает эпилог полностью. Наконец, в пересказ Догель не входит вставная легенда про Эль-Ахрайраха и Черного Кролика Инле, полубожественного персонажа кроличьей мифологии, который приходит за каждым кроликом в момент его смерти. По сюжету легенды Эль-Ахрайрах, пытаясь спасти свое племя, заключает сделку с Черным Кроликом и подвергается ужасным мучениям: ему постепенно отрезают усы, хвост и уши, сбрасывают в чумную яму и т.д. Вероятнее всего, переводчик не включает этот фрагмент в пересказ как потенциально способный травмировать детскую психику.

Наиболее заметно подобные манипуляции в пересказе Догель проявляются на персонажном уровне. Отличие романа Адамса от традиционной сказки заключается в том, что фэнтези не предполагает однозначной трактовки героев, деления их на «хороших»и и «плохих». Если сказка создается с установкой на вымысел, то автор фэнтези моделирует реалистичный и логично устроенный мир, в котором нет четкого деления на «черное» и «белое». Положительный герой не может быть идеально положительным, так же как и отрицательный герой не может быть абсолютным воплощением зла, однако именно эту тенденцию можно наблюдать в пересказе Догель, приближающей героев к схематическому делению на «хороших» и «плохих», чтобы сделать их более однозначными и понятными для читателя-ребенка. Так, если в оригинале показана эволюция протагониста Ореха, который из сомневающегося и нерешительного кролика-аутсайдера вырастает в настоящего мудрого и справедливого лидера, то у Догель этот персонаж задан изначально и остается статичным. Для моделирования заданного обра- 
за Догель активно изменяет модальность высказываний Ореха, так что в его речи по сравнению с оригиналом сокращаются вставные конструкции, выражающие сомнение и неуверенность, начинают преобладать повелительное наклонение и глаголы долженствования:

Пересказ Е.В. Догель

Здесь мы можем хоть целый день проспать! - сказал Орех. - Только кто-нибудь должен все время стоять на страже. Я буду первblм! [25. C. 31]
Перевод Т.Н. Чернышовой Здесь можно спать хоть целый день, - сказал Орех. - Но, помоему, пусть лучие кто-нибудь все же останется сторожить. Если вы согласны, я подежурю первыц $<\ldots>$ [26. C. 58].

Характерным является отличное от оригинала употребление притяжательных местоимений в пересказе: для Ореха вся компания - это «его» кролики, за которых он как лидер несет ответственность.

Главный антагонист романа Генерал Дурман также неоднозначный персонаж. Он единственный, чьей предыстории автор посвящает отдельную главу, из которой читатели могут узнать, под влиянием каких жизненных обстоятельств формируется личность Дурмана. Это кролик с очень сложной судьбой: почти всю его семью убили люди, а мать растерзал хищник у него на глазах. Дурману удалось не только выжить в ситуации, когда большинство кроликов погибло бы, но и подчинить себе племя диких кроликов и основать свою колонию, в которой постепенно сложился тоталитарный режим правления (в отличие от колонии Ореха и его друзей, основанной на демократических принципах). Однако рассказывая предысторию Генерала, писатель показывает его с другой стороны. Дурман - прирожденный лидер, умный, мужественный, но суровый и беспощадный к врагам. Создавая колонию, он мечтает не только о безграничной власти, но и о мирной и счастливой жизни для своих кроликов. На начальном этапе строительства колонии Генерал способен на преданность, самопожертвование и заботу - качества, которые не может априори иметь сказочный злодей: «From the first the warren prospered. Woundwort watched 
over them with a tireless zeal that won their loyalty even while they feared him. When the does stopped digging, Woundwort himself went on with their work while they slept. $<\ldots>$ Woundwort was no mere bully. He knew how to encourage other rabbits and to fill them with a spirit of emulation. It was not long before his officers were asking to be allowed to lead patrols» [13. Р. 304]. Проведенный анализ показывает, что в пересказе Догель образ генерала значительно скорректирован; описания, которые могут заставить читателя сочувствовать персонажу, опущены или значительно искажены:

Пересказ Е.В. Догель Зверобой следил за всем с неутомимым рвением и дрался с крысами, белками, сороками и один раз даже с вороной. $<\ldots>$ [25. C. 94].
Перевод Т.Н. Чернышовой Жизнь в городке пошла на лад. Дурман отдавал ему всю душу, чем завоевал сердца кроликов куда больше, чем силой. Если крольчихи уставали рыть норы, он отпускал их поспать, а сам становился на их место. $<\ldots>$ Дурман был не просто громила, он умел и подбодрить своих, и зажечь в них жажду соревнования [26. С. 384-385].

Проведенный сравнительно-сопоставительный анализ двух русскоязычных версий романа Р. Адамса демонстрирует, что амбивалентный текст кроссовер-литературы представляет особую переводческую проблему в силу заложенного в нем потенциала одновременно апеллировать к читателю разных возрастных групп, невзирая на их разный языковой, социальный, мировоззренческий и общекультурный опыт и уровень развития когнитивных способностей. При переносе такого текста в инокультурную среду универсальность адресации не сохраняется автоматически, вследствие чего произведение может появиться в разных сегментах книжного рынка. Поскольку кроссовер-литература не только жанровая, но и маркетинговая категория, решение о том, как переведенное произведение будет функционировать на принимающем книжном рынке и в какой возрастной сегмент оно попадет, зависит от инициатора перевода, чаще всего издателя. Переводчик, в свою очередь, рассматривает текст оригинала как информационное предложение, 
которое он будет модифицировать не только в зависимости от языковых особенностей и функции источника в оригинальной культуре, но главным образом в зависимости от скопоса перевода, который формулируется с учетом экстратекстуальных факторов (ситуации коммуникации, цели перевода, особенностей автора и получателя). Для перевода кроссовер-литературы, ключевым в жанровом определении которой является фактор целевой аудитории, наиболее релевантными представляются функциональный подход и теория скопоса, позволяющие при выборе переводческих решений ориентироваться не на микро-, а на макротекст. Если в принимающей культуре произведение кроссовер-литературы планируется к выпуску в сегменте детской литературы, то текст оригинала подвергнется существенной адаптации при переводе уже в силу специфики детской литературы, к которой в любой культуре предъявляются особые требования. Этот процесс в чем-то схож с возрастной адаптацией классики «взрослой» литературы, в связи с чем ошибочно было бы считать полученный переводческий продукт фальсификацией оригинала. Таким же заблуждением было бы считать адаптированную версию «плохим» переводом, поскольку в рамках теории скопоса качество перевода оценивается соответствием выбранной стратегии поставленной цели, а достижение этой цели определяется успехом у целевой аудитории, как в случае с двумя русскоязычными версиями романа Р. Адамса «Обитатели холмов», каждая из которых регулярно переиздается и пользуется успехом у читателей разных возрастных категорий.

\section{Лumepamypa}

1. Арзамасцева И.Н., Николаева С.А. Детская литература : учеб. для студ. вузов по специальности «Педагогика и методика нач. образования». М. : Академия, 2009. $576 \mathrm{c}$.

2. Мяоэтс О.Н. Конфликт отцов и детей: для кого пишут детские книги и кто их читает? // Детские чтения. 2014. № 2(6). С. 170-183.

3. Beckett S.L. Crossover Fiction: Global and Historical Perspectives. London: Routledge, 2008. 346 p.

4. Reiss K., Vermeer H.J. Grundlegung einer allgemeinen Translationstheorie. Tubingen : Walter de Gruyter, 1984. 253 p. 
5. Nord C. Text Analysis in Translation: Theory, Methodology, and Didactic Application of a Model for Translation-Oriented Text Analysis. Amsterdam ; New York : Rodopi, 2005. 274 p.

6. Gritsenko M. Functional Approach to Translation of Crossover Fiction // Science and Education a New Dimension. Philology. 2015. Vol. III(10), is. 47. P. 23-25.

7. Klingberg G. Children's fiction in the hands of the translators. Malmö : Libervörlag, $1986.90 \mathrm{p}$.

8. Shavit Z. Poetics of Children's Literature. Athens ; London : The University of Georgia Press, 1986. $216 \mathrm{p}$

9. Bastin G.L. Adaptation // Baker, M. \& Saldanha, G. (ed.) Routledge Encyclopedia of Translation Studies. London : Routledge, 2009. P. 3-5.

10. Puurtinen T. Syntax, Readability and Ideology in Children's Literature // Meta: Translators' Journal. 1998. Vol. 43, № 4. P. 524-533.

11. Oittinen R. Translating for children. New York ; London : Garland Publishing Inc., 2000. $205 \mathrm{p}$.

12. Shavit Z. Translation of children's literature as a function of its position in a literary polysystem // Poetics Today. 1981. Vol. 2 (4). P. 171-179.

13. Adams R. Watership Down. London : Rex Collings, 1972. 476 p.

14. Campbell J. The Hero with a Thousand Faces. Princeton : Princeton University Press, 1949. $432 \mathrm{p}$.

15. Юнг К.Г. Психология бессознательного. М. : Когито-Центр, 2010. 352 с.

16. Rothen K.J., Langston B. Hazel, Fiver, Odysseus, and You: An Odyssey into Critical Thinking // The English Journal. National Council of Teachers of English. 1987. Vol. 76 (3). P. 56-59.

17. Kitchell K.F.Jr. The Shrinking of the Epic Hero: From Homer to Richard Adams's Watership Down // Classical and Modern Literature. 1986. № 7 (1). P. 13-30.

18. Rateliff J.D. Classics of Fantasy. URL: https://web.archive.org/ web/20081228025527/http://ww2.wizards.com/books/Wizards/default.aspx?doc=main classicswatership (дата обращения: 9.09.2018).

19. Lockley R. The Private Life of the Rabbit : An Account of the Life History and Social Behavior of the Wild Rabbit. New York : Macmillan, 1964. $172 \mathrm{p}$.

20. Flanagan D. To Each Generation Its Own Rabbits // Wilson Library Bulletin. 1974. № 49. $153 \mathrm{p}$.

21. Kemball-Cook J. Richard Adams // Kirkpatrick D.L. (ed.) Twentieth-Century Children's Writers. New York : Macmillan International Higher Education, 1978. P. 910 .

22. Kadish R. Whose Parable Is It Anyway? URL: https://web.archive.org/ web/20111004081325/http://momentmag.com/moment/issues/2011/10/speakingvolume s.html (дата обращения: 9.09.2018).

23. Chapman E.L. The Shaman as Hero and Spiritual Leader: Richard Adams' Mythmaking in Watership Down and Shardik // Mythlore: A Journal of J.R.R. Tolkien, C.S. Lewis, Charles Williams, and Mythopoeic Literature. 1978. № 5 (2). P. 7-11.

24. The Economist. Pick of the Warren. 23rd December, 1972. 
25. Адамс Р. Удивительные приключения кроликов / пер. с англ. Е.В. Догель. М. : Детская литература, 1988. 288 с.

26. Адамс Р. Обитатели холмов / пер. с англ. Т.Н. Чернышова. М. : АзбукаTeppa, 1996. $591 \mathrm{c}$.

27. Pawling C. Watership Down: Rolling back the 1960s // Pawling C. (ed.) Popular Fiction and Social Change. London : MacMillan Press, 1984. P. 212-235.

28. Аромштам М. Нужны ли детям книги о смерти. URL: http://www.papmambook.ru/articles/970/ (дата обращения: 9.09.2018).

THE TRANSLATION CHALLENGES OF CROSSOVER FICTION (R. ADAMS'S WATERSHIP DOWN AND ITS RUSSIAN VERSIONS)

Tekst. Kniga. Knigoizdanie - Text. Book. Publishing, 2018, 18, pp. 24-43.

DOI: $10.17223 / 23062061 / 18 / 2$

Gorenintseva Valentina N., Tomsk State University (Tomsk, Russian Federation). E-mail: anatol_valya@mail.ru

Keywords: crossover fiction, universal addressee, skopos of translation, translation commissioner, adaptation strategies, translation for children.

The research focuses on the problem of translating crossover fiction caused by its simultaneous addressing a diverse cross-generational audience due to the blurred borderline between traditionally separate readerships. Resulting from the combination of two structural models - one archetypal and addressed to children and the other experimental and addressed to the adults - the crossover fiction does not necessarily retain its potential to appeal to multiple audience in the target-culture. In the process of translation, this hybrid literature genre allows various approaches to harnessing its crossover potential ranging from cooperation with its double audience to the ultimate confrontation and rejection, when the adults and children cannot share their reading experience. Since crossover fiction is not only a literary phenomenon, but also a marketing category, the translation commissioner often plays a crucial role in determining how the translated text will function in the target culture. The translator, in turn, considers the source-text as an information field, which (s)he modifies not only depending on the linguistic features and source function of the text in the original culture, but mainly depending on extratextual parameters: the target-text purpose (skopos) and the targettext audience. The commissioner's decision to position the text under translation in the book market opens several options in terms of the target age group of the reader-insituation, which may be mixed audience, adults, or children. Of them all, translating for the latter seems to be most disputable and challenging, as children's literature of any culture and epoch is more subject to regulations and restrictions than that for adults. The author argues that adaptation, or domestication, is inevitable in translating a crossover text for children. Though this product is not translation proper and thus should be marked as an abridgement or adaptation, it can represent the original work of literature in the target-culture. The comparative analysis of two Russian translations of R. Adams's epic fantasy Watership Down - one by E.V. Dogel published by the Detskaya 
literatura Publishing House in 1988 under the title Udivitelnye priklyucheniya krolikov and the other by T.N. Chernyshova published by Azbuka-Terra Publishing House as Obitately kholmov - clearly demonstrates the possible changes (genre model adaptation, manipulation with style, integrity, complexity, ethical and axiological component) that happen to the double focus of the origin in terms.

\section{References}

1. Arzamastseva, I.N. \& Nikolayeva, S.A. (2009) Detskaya literatura [Children's Literature]. Moscow: Akademiya.

2. Myaoets, O.N. (2014) Conflict of "Fathers and Sons": Who are the Children's Books Witten For and Who Reads Them? Detskie chteniya - Children's Readings: Studies in Children's Literature. 2(6). pp. 170-183. (In Russian).

3. Beckett, S.L. (2008) Crossover Fiction: Global and Historical Perspectives. London: Routledge.

4. Reiss, K. \& Vermeer, H.J. (1984) Grundlegung einer allgemeinen Translationstheorie [Foundation of a General Translation Theory]. Tubingen: Walter de Gruyter.

5. Nord, C. (2005) Text Analysis in Translation: Theory, Methodology, and Didactic Application of a Model for Translation-Oriented Text Analysis. Amsterdam; New York: Rodopi.

6. Gritsenko, M. (2015) Functional Approach to Translation of Crossover Fiction. Science and Education a New Dimension. Philology. 3(10). pp. 23-25.

7. Klingberg, G. (1986) Children's fiction in the hands of the translators. Malmö: Libervörlag.

8. Shavit, Z. (1986) Poetics of Children's Literature. Athens; London: The University of Georgia Press.

9. Bastin, G.L. (2009) Adaptation, In: Baker, M. \& Saldanha, G. (eds) Routledge Encyclopedia of Translation Studies. London: Routledge. pp. 3-5.

10. Puurtinen, T. (1998) Syntax, Readability and Ideology in Children's Literature. Meta: Translators' Journal. 43(4). pp. 524-533. DOI: 10.7202/003879ar

11. Oittinen, R. (2000) Translating for Children. New York; London: Garland Publishing Inc.

12. Shavit, Z. (1981) Translation of children's literature as a function of its position in a literary polysystem. Poetics Today. 2(4). pp. 171-179.

13. Adams, R. (1972) Watership Down. London: Rex Collings.

14. Campbell, J. (1949) The Hero with a Thousand Faces. Princeton: Princeton University Press.

15. Jung, K.G. (2010) Psikhologiya bessoznatel'nogo [Psychology of the Unconscious]. Moscow: Kogito Tsentr.

16. Rothen, K.J. \& Langston, B. (1987) Hazel, Fiver, Odysseus, and You: An Odyssey into Critical Thinking. The English Journal. National Council of Teachers of English. 76(3). pp. 56-59. DOI: 10.2307/818545 
17. Kitchell, K.F.Jr. (1986) The Shrinking of the Epic Hero: From Homer to Richard Adams's Watership Down. Classical and Modern Literature. 7(1). pp. 13-30.

18. Rateliff, J.D. (2008) Classics of Fantasy. [Online] Available from: https://web.archive.org/web/20081228025527/http://ww2.wizards.com/books/Wizards/ default.aspx?doc=main_classicswatership. (Accessed: 9th September 2018).

19. Lockley, R. (1964) The Private Life of the Rabbit : An Account of the Life History and Social Behavior of the Wild Rabbit. New York: Macmillan.

20. Flanagan, D. (1974) To Each Generation Its Own Rabbits. Wilson Library Bulletin. $49.153 \mathrm{p}$.

21. Kemball-Cook, J. (1978) Richard Adams. In: Kirkpatrick D.L. (ed.) TwentiethCentury Children's Writers. New York: Macmillan International Higher Education. pp. 9-10.

22. Kadish, R. (2011) Whose Parable Is It Anyway? [Online] Available from: https://web.archive.org/web/20111004081325/http://momentmag.com/moment/issues/2 011/10/speakingvolumes.html. (Accessed: 9th September 2018).

23. Chapman, E.L. (1978) The Shaman as Hero and Spiritual Leader: Richard Adams' Mythmaking in Watership Down and Shardik. Mythlore: A Journal of J.R.R. Tolkien, C.S. Lewis, Charles Williams, and Mythopoeic Literature. 5(2). p. 7-11.

24. The Economist. (1972) Pick of the Warren. 23rd December.

25. Adams, R. (1988) Udivitel'nye priklyucheniya krolikov [Amazing Adventures of Rabbits]. Translated from English by E.V. Dogel. Moscow: Detskaya literatura.

26. Adams, R. (1996) Obitateli kholmov [Dwellers of the Hills]. Translated from English by T.N. Chernyshova. Moscow: Azbuka-Terra.

27. Pawling, C. (1984) Watership Down: Rolling back the 1960s. In: Pawling, C. (ed.) Popular Fiction and Social Change. London: MacMillan Press. pp. 212-235.

28. Aromstam, M. (n.d.) Nuzhny li detyam knigi o smerti [Do children need books about death?]. [Online] Available from: http://www.papmambook.ru/articles/970/. (Accessed: 9th September 2018). 